\title{
Serum Hydroxybutyrate Dehydrogenase in Myocardial Infarction
}

\author{
J. STUART,* M.B., CH.B. ; I. C. CRAWFORD, $\dagger$ M.B., CH.B., M.R.C.P.ED. ; JEAN FORSHALL, $\ddagger$ B.SC. ; \\ J. A. OWEN, $\ddagger$ B.SC., M.D., PH.D., M.C.P.A., M.C.PATH.
}

Brit. med. F., 1965, 1, 423-425

The determination of serum $\alpha$-hydroxybutyrate dehydrogenase (S.H.B.D.) has been reported to be a useful test in the diagnosis of myocardial infarction (Elliott, Jepson, and Wilkinson, 1962 ; Konttinen and Halonen, 1962 ; Rosalki, 1963). These reports were based on studies carried out with a spectrophotometric method for the measurement of S.H.B.D. Rosalki (1962) described a simple colorimetric procedure which has brought the test within the scope of most hospital laboratories. We have used this procedure to measure S.H.B.D. in patients admitted to hospital with features of myocardial infarction and present here our experience.

\section{Methods}

S.H.B.D. was measured according to the method of Rosalki (1962), using an incubation period of 60 minutes, and serum glutamic oxaloacetic transaminase (S.G.O.T.) was measured according to the procedure of Reitman and Frankel (1957). Sera were separated from red cells within three hours of collection, and were either analysed immediately or stored until required at $4^{\circ} \mathrm{C}$. for periods not exceeding 48 hours. Specimens appearing to the unaided eye to have been haemolysed were discarded.

Normal ranges for S.H.B.D. and S.G.O.T. were obtained by analysing sera obtained from healthy blood donors. The mean S.H.B.D. $(\mathrm{N}=52)$ was 71 units $/ 1$. (1 unit $/ 1$. = 1 I.U. $/ 1$.) with a standard deviation of 16 units/1. and an actual range of $42-$ 106 units $/ 1$. The upper limit of normal $(N=30)$ for S.G.O.T. was 30 units $/ \mathrm{ml}$. (1 unit $=0.5$ I.U. $/ 1$.) ; the mean and full range were not defined because all values below 20 units $/ \mathrm{ml}$. were recorded only as $<20 \mathrm{units} / \mathrm{ml}$. However, only four values lay between 20 and 30 units $/ \mathrm{ml}$.; the rest were under 20 units $/ \mathrm{ml}$.

E.C.G. recordings were standard 12-lead tracings, and all were assessed by one of us (I. C. C.).

\section{Material}

The patients studied were admitted to the Royal Infirmary, Edinburgh, during 1963 and were selected from those who presented one or more features-for example, chest pain, acute dyspnoea, collapse, vomiting-raising the possibility that the patient had myocardial disease. They were grouped as follows:

Group 1 (100 cases).-These were patients in whom a clinical diagnosis of recent myocardial infarction was supported by the demonstration of E.C.G. changes conforming to the World Health Organization (1959) criteria for "very probable" myocardial infarction. Seventeen patients in this group died within one month of the infarction. Necropsy was carried out in 14 of these and the diagnosis confirmed in all 14.

* University Department of Clinical Chemistry, Royal Infirmary, Edinburgh. New address, Regisurar Clinical Pathologist, Department of
Haematology, Royal Infirmary, Edinburgh.

† Department of Cardiology, Royal Infirmary, Edinburgh.

¥ University Department of Clinical Chemistry, Royal Infirmary, Edinburgh.
Group 2 (40 cases).-These were patients considered on the basis of all available evidence, excluding S.H.B.D. values, to have ischaemic myocardial disease without infarction. In 17 cases the E.C.G. showed changes suggesting ischaemic cardiac disease or left ventricular strain; in the remainder it was normal. In 32 cases the S.G.O.T. was determined at least once during the first three days following the acute episode; all values were normal.

Group 3 (24 cases).-These were patients in whom the presenting clinical features were eventually shown not to be due to myocardial infarction or ischaemic cardiac disease (Table IV).

Patients in whom a clinical diagnosis of myocardial infarction was not supported by the presence of E.C.G. changes conforming with W.H.O. criteria for "very probable" myocardial infarction have not been considered in this report because of the uncertainty in such a diagnosis.

\section{Resuits}

\section{Group 1 : Myocardial Infarction}

S.H.B.D. values in this group of patients are summarized in Table I. After the acute episode the mean S.H.B.D. increased, reaching a maximum on day 3. (The first 24-hour period following the incident was designated day 1.) Thereafter the mean value slowly decreased. On every day, however, there was some overlap between the results in this group of patients and the normal range. This was minimal over days 2 to 7 inclusive, when an average of $95 \%$ of results were above the upper limit of normal and an average of $90 \%$ were above 140 units $/ 1$.

TABLE I.-S.H.B.D. Values in 100 Patients with Myocardial Infarction

\begin{tabular}{|c|c|c|c|c|c|c|c|c|c|c|}
\hline & \multicolumn{10}{|c|}{ Days after Infarction } \\
\hline & $1^{*}$ & 2 & 3 & 4 & 5 & 6 & 6 & 8 & 9 & 10 \\
\hline $\begin{array}{l}\text { No. of results } \ldots \\
\text { S.H.B.D. } \\
\text { (units/1.) }\end{array}$ & 28 & 56 & 53 & 54 & 43 & 35 & 27 & 13 & 10 & 9 \\
\hline $\begin{array}{l}\text { Mean } \\
\text { Lowest result } \\
\text { Highest result }\end{array}$ & $\begin{array}{r}198 \\
80 \\
400\end{array}$ & $\begin{array}{r}332 \\
80 \\
915\end{array}$ & $\begin{array}{r}398 \\
85 \\
1,200\end{array}$ & $\begin{array}{r}383 \\
67 \\
975\end{array}$ & $\begin{array}{r}323 \\
35 \\
1,135\end{array}$ & $\begin{array}{r}319 \\
92 \\
730\end{array}$ & $\begin{array}{r}283 \\
95 \\
755\end{array}$ & $\begin{array}{r}205 \\
75 \\
600\end{array}$ & $\begin{array}{r}181 \\
85 \\
350\end{array}$ & $\begin{array}{r}157 \\
30 \\
330\end{array}$ \\
\hline$\%$ of results over & 89 & 95 & 94 & 96 & 98 & 94 & 92 & 62 & 70 & 67 \\
\hline $\begin{array}{c}\% \text { of results over } \\
140 \text { units } / 1 .\end{array}$ & 64 & 87 & 89 & 93 & 88 & 91 & 89 & 62 & 60 & 56 \\
\hline
\end{tabular}

* The first 24-hour period following the acute episode was designated day 1 .

S.G.O.T. values are summarized in Table II. A peak value was reached on day 2 . The percentage of results above the upper limit of normal ( $30 \mathrm{units} / \mathrm{ml}$.) also reached a maximum on day 2 .

TABLE II.-S.G.O.T. Values in 100 Patients with Myocardial Infarction

\begin{tabular}{|c|c|c|c|c|c|c|c|c|c|c|}
\hline & \multicolumn{10}{|c|}{ Days after Infarction } \\
\hline & 1 & 2 & 3 & 4 & 5 & 6 & 7 & 8 & 9 & 10 \\
\hline $\begin{array}{l}\text { No. of results } \\
\text { Mean S.G.O.T. (units } / \mathrm{ml} \text {.) } \\
\% \text { of results over } 30 \text { units } / \mathrm{mi} .\end{array}$ & $\begin{array}{l}40 \\
56 \\
43\end{array}$ & $\begin{array}{l}63 \\
90 \\
87\end{array}$ & $\begin{array}{l}54 \\
61 \\
70\end{array}$ & $\begin{array}{l}55 \\
55 \\
55\end{array}$ & $\begin{array}{l}45 \\
35 \\
29\end{array}$ & $\begin{array}{l}33 \\
49 \\
36\end{array}$ & $\begin{array}{l}25 \\
36 \\
16\end{array}$ & \begin{tabular}{|l|}
13 \\
28 \\
15
\end{tabular} & $\begin{array}{l}10 \\
26 \\
10\end{array}$ & $\begin{array}{l}10 \\
22 \\
10\end{array}$ \\
\hline
\end{tabular}


There was a tendency for patients who died within four weeks of the infarction to have higher S.H.B.D. values at each stage than those who survived. However, there was some overlap between results in those who died and in those who survived. Thus during the first four days after the infarction approximately one patient in three who subsequently died had an S.H.B.D. value below the mean value of those who survived. There was a similar tendency for patients who died to have higher S.G.O.T. values than those who survived, but again there was much overlap.

\section{Group 2 : Ischaemic Myocardial Disease}

In this group the mean S.H.B.D. showed practically no change with time (Table III). Fifteen patients had one or more values above the upper limit of normal, but only one patient had a value above 140 units/l. The mean S.H.B.D. values in patients with abnormal E.C.G.s were on the average $11 \%$ higher during days $1-6$ than those in patients with normal E.C.G.s.

Table III.-S.H.B.D. Values in Patients with Ischaemic Cardiac Disease

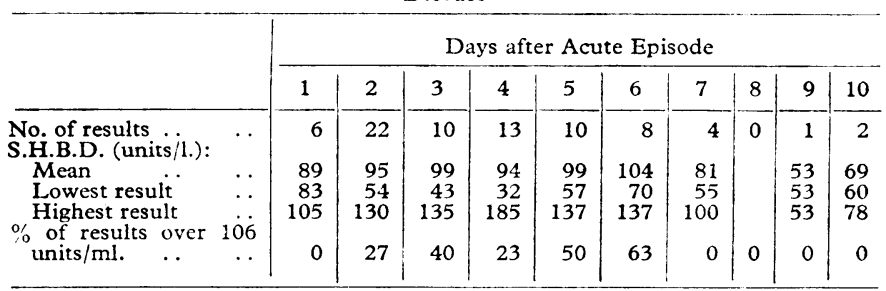

The data in Table III suggest superficially that abnormal results were more frequent in this group during days 2-6 than at other times after the infarction. However, the observed percentage of abnormal results does not differ significantly $\left(x^{2}=7 ; P=0.4\right)$ from that expected on the basis that results did not vary with time.

\section{Group 3 : Extracardiac Conditions}

Results in this group of patients are summarized in Table IV. A raised S.H.B.D. was recorded at some time or another in about a third of the patients. Three patients had a maximum value exceeding 140 units/l.

TABLE IV.-S.H.B.D. Values in Extracardiac Conditions

\begin{tabular}{|c|c|c|c|c|c|}
\hline \multirow{2}{*}{ Diagnosis } & \multirow{2}{*}{$\begin{array}{l}\text { No. of } \\
\text { Cases }\end{array}$} & \multirow{2}{*}{$\begin{array}{c}\text { Range of } \\
\text { Maximum } \\
\text { S.H.B.D. Values } \\
\text { (Units/1.) }\end{array}$} & \multicolumn{3}{|c|}{$\begin{array}{c}\text { No. of Patients with } \\
\text { Maximum S.H.B.D. } \\
\text { Values }\end{array}$} \\
\hline & & & $<106$ & $106-140$ & $\begin{array}{l}>140 \\
\text { unit/1. }\end{array}$ \\
\hline \multirow{2}{*}{$\begin{array}{l}\text { Pulmonary infarct } \\
\text { Bronchitis/pneumonia.. } \\
\text { Cholecystitis/biliary } \\
\text { obstruction .. }\end{array}$} & $\begin{array}{r}6 \\
13\end{array}$ & $\begin{array}{l}85-165 \\
45-245\end{array}$ & $\begin{array}{l}3 \\
8\end{array}$ & $\begin{array}{l}2 \\
3\end{array}$ & $\begin{array}{l}1 \\
2\end{array}$ \\
\hline & 5 & $60-110$ & 4 & 1 & 0 \\
\hline
\end{tabular}

\section{Discussion}

Our findings confirm early reports (Elliott et al., 1962 ; Konttinen and Halonen, 1962 ; Pagliaro and Notarbartolo, 1962 ; Rosalki, 1963) that S.H.B.D. is elevated, often markedly, in patients who have recently suffered a myocardial infarct. However, values were elevated also in some patients with myocardial ischaemia. Rosalki (1963), in contrast, found no instance of an abnormal S.H.B.D. in 31 patients with angina pectoris or coronary insufficiency but without a myocardial infarction. It should be noted, however, that the upper limit of normal (mean +2 S.D.) found by Rosalki (1962), using a spectrophotometric procedure, was approximately $15 \%$ higher than the value we obtained, using the colorimetric procedure, though our value was very close to that obtained by Preston, Batsakis, and Briere (1964), who also used the colorimetric method. Possibly this discrepancy results from differences in the choice of normal subjects.

We also found raised S.H.B.D. values in some patients with pulmonary infarction, pneumonia, or bronchitis, and in one with acute cholecystitis. Elevation of S.H.B.D. in various extracardiac diseases-namely, haemolytic disease, megaloblastic anaemia, leukaemia, malignancy, hepatobiliary disease, and muscular dystrophy-has previously been reported (Elliott et al., 1962 ; Elliott and Wilkinson, 1963 ; Rosalki, 1963 ; Preston et al., 1964).

Since elevation of S.H.B.D. is not confined to patients with myocardial infarction it is necessary, in using this determination as a diagnostic test for myccardial infarction, to define a critical level (above the upper normal level) in order to reduce the number of "false-positive" results to a reasonable extent. Inspection of our data suggested that the value of 140 units/1. was appropriate as such. Thus in patients with myocardial infarction the proportion of results exceeding this value on days 2 to 7 inclusive averaged $90 \%$ (Table I), and only four patients who had one or more determinations performed during this period failed to show any values above 140 units/l. In contrast only one out of 39 patients with myocardial ischaemia and only three patients with extracardiac disease (Table IV) had one or more S.H.B.D. values exceeding this value. Thus taking a critical value of 140 units/1. instead of the upper limit of normal (found in blood donors) increased the specificity of the test for myocardial infarction. Further increase in specificity could possibly be obtained by measuring the serum lactate dehydrogenase (S.L.D.H.)/S.H.B.D. ratio (Elliott and Wilkinson, 1961) or by determining the S.L.D.H. isoenzyme pattern (Preston et al., 1964).

The diagnostic value of S.H.B.D. determination can be compared with that of S.G.O.T. determination on the basis of the proportion of abnormal results at various times after the infarction. Our results (Tables I and II) indicate that at all stages the S.H.B.D. is more often abnormal. Thus even on day 1 there was a higher proportion of abnormal S.H.B.D. values than of abnormal S.G.O.T. values. It should be noted that our normal upper limit for S.G.O.T.-namely, 30 units/ $\mathrm{ml}$.-is lower than what is often accepted-namely, 40 units $/ \mathrm{ml}$. -but is in keeping with values obtained by many investigators -for example, Karmen (1955), Baron, Alexander, Bell, and Oakley (1958), and Rowell and Smith (1959).

Even when an S.H.B.D. value of 140 units/1. was taken as a critical level instead of the upper limit of normal, determination of S.H.B.D. was a more sensitive diagnostic test at all times. By day 5 S.G.O.T. values were normal in approximately two out of three patients with myocardial infarction, whereas even by day 10 only one in five patients had normal S.H.B.D. values.

The comparative diagnostic efficiency of S.H.B.D. results and E.C.G. recordings cannot be determined from our data, since we used the latter in classifying patients. Others (Trethewie, 1958 ; Woods, Laurie, and Smith, 1963) have reported that a 12-lead E.C.G. tracing provides diagnostic evidence in $80-90 \%$ of patients with recent myocardial infarction.

Lastly, though S.H.B.D. values following myocardial infarction tended to be higher in the patients who died during the subsequent four weeks than in those who survived, the overlap in results was too great for values to be of much prognostic significance in individuals. Similar conclusions have been reached concerning S.G.O.T. measurements (Wilkinson, 1962).

\section{Summary}

Serial serum $\alpha$-hydroxybutyrate dehydrogenase determinations have been carried out on 100 patients with recent 
myocardial infarction, 40 patients with ischaemic cardiac disease, and 24 patients with other conditions.

S.H.B.D. values were found to be elevated, often markedly, at some stage in every patient with recent myocardial infarction. Smaller elevations were found in some patients with myocardial ischaemia, pulmonary infarction, pneumonia, or bronchitis.

An S.H.B.D. value of 140 units/1. has been chosen as the most appropriate value for differentiating between recent myocardial infarction and other conditions, including myocardial ischaemia. In 9 out of 10 patients with myocardial infarction S.H.B.D. results are above this level at some stage within three days of the acute episode, and the elevation persists for 10 days in four patients out of five. This is of particular diagnostic value when the patient is admitted some days after the event.

The diagnostic efficiency of S.H.B.D. determination is greater than that of S.G.O.T. determination, especially in the period 3 to 10 days after the acute episode, and compares favourably with that of the E.C.G.

S.H.B.D. values after myocardial infarction appear to be of little prognostic value.
We should like to thank the various physicians who have allowed us to study patients under their care. We are grateful to Dr. M. F. Oliver for his helpful criticism during this study, and to Dr. R. A. Cumming for the samples of normal blood.

\section{REFERENCES}

Baron, D. N., Alexander, C. P., Bell, J. L., and Oakley, C. M. (1958). Quart. F. Med., 27, 533.

Elliott, B. A., Jepson, E. M., and Wilkinson, J. H. (1962). Clin. Sci. 23, 305 . and Wilkinson, J. H. (1961). Lancet, 1, 698

Karmen (1963). Clin. Sci., 24, 343.

A. (1955). 7. clin. Invest. 34, 131.

Konttinen, A., and Halonen, P. I. (1962). Amer. 7. Cardiol., 10, 525.

Pagliaro, L., and Notarbartolo, A. (1962). Lancet, 1, 1043.

Preston, J. A., Batsakis, J. G., and Briere, R. O.'(1964). Amer. F. clin. Path., 41, 237.

Reitman, S., and Frankel, S. (1957). Ibid., 28, 56.

Rosalki, S. B. (1962). F. clin. Path., 15, 566.

(1963). Brit. Heart 7., 25, 795.

Rowell, N. R., and Smith, A. J. (1959). Brit. med. f., 2, 459.

Trethewie, E. R. (1958). Ibid., 2, 1428.

Wilkinson, J. H. (1962). An Introduction to Diagnostic Enzymology. Arnold, London.

Woods, J. D., Laurie, W., and Smith, W. G. (1963). Lancet, 2, 265.

World Health Organization (1959). Tech. Rep. Ser., No. 168.

\title{
Arcus Senilis in Middle-aged Men
}

\author{
G. M. MCANDREW,* M.B., M.R.C.P.ED. ; D. OGSTON,* M.A., M.B., PH.D., M.R.C.P.ED.
}

Brit. med. F., 1965, 1, 425-427

The possibility that an arcus senilis might provide a readily recognized manifestation of the presence of atherosclerosis has intrigued clinicians for many years. Most recent work, however, suggests that the incidence of arcus senilis depends not on the presence of atherosclerosis but on advancing age (Rodstein and Zeman, 1963 ; Lindholm, 1960). Agreement is not yet complete: Pomerantz (1962) found that the incidence of arcus senilis was greater in patients who had sustained a myocardial infarction, while Rodstein and Zeman (1963) noted a significant correlation between the degree of arcus senilis and the incidence of electrocardiographic abnormalities in elderly patients.

We have compared the incidence and degree of arcus senilis in two groups of middle-aged subjects, one group comprising patients who had suffered a myocardial infarction and the second group patients without clinical or electrocardiographic evidence of ischaemic heart disease. We have further studied the group of post-cardiac-infarction patients to determine whether the presence of an arcus senilis in this group is associated with a high serum-cholesterol level, a raised bloodpressure, or a more massive physique.

\section{Methods}

Serum Cholesterol.-This was estimated on a Technicon Autoanalyzer as described by Green et al. (1963).

Body. Build.-Height was measured to the nearest $\frac{1}{4}$ in. $(0.6 \mathrm{~cm}$.). Weight, without shoes and jacket, was measured to the nearest $\frac{1}{4} \mathrm{lb}$. $(0.11 \mathrm{~kg}$.) ; $4 \mathrm{lb}$. (1.8 kg.) was subtracted from this weight to account for the remaining clothing. The

\footnotetext{
* Lecturer in Medicine, University of Aberdoen.
}

ponderal index, a measure of body mass, was estimated according to the formula:

$$
\text { P.I. }=\frac{\text { Height in inches }}{v^{\prime} \text { Weight in } \mathrm{lb} .}
$$

This index has been discussed by Sheldon et al. (1940).

Subjects.-(a) 100 Post-cardiac-infarction Patients. These had been admitted to hospital 3 to 53 months previously, at which time electrocardiographic evidence of cardiac infarction was present. All were receiving therapeutic doses of phenindione, the Quick one-stage prothrombin time being kept between two and a half and three times the control. All were men aged 40 to 69 at the time of this study.

(b) 100 Control Patients. These were male patients aged 40 to 69 admitted to hospital suffering from a variety of medical disorders. All had electrocardiographic tracings free from ischaemic changes and none had a history or clinical evidence of occlusive vascular disease. The number in each age-decade was chosen to match the number in the post-cardiac-infarction decades.

Classification of Arcus Senilis.-Assessment of arcus senilis in all patients was made by the same observer with the aid of artificial light. The following grades were recognized: grade 0 , no observable arcus senilis ; grade 1 , either an upper or a lower arc of opacity in the cornea; grade 2 , a lower and an upper arc of opacity in the cornea; grade 3, a ring of opacity in the cornea, although not prominent, seen to be complete on close scrutiny ; and grade 4, a prominent, complete ring of opacity in the cornea. Grade 4 would be referred to as a marked arcus senilis in clinical practice.

All blood-pressure readings were carried out by a single observer. Blood samples for estimation of serum cholesterol were withdrawn between 2 and 3 p.m. 